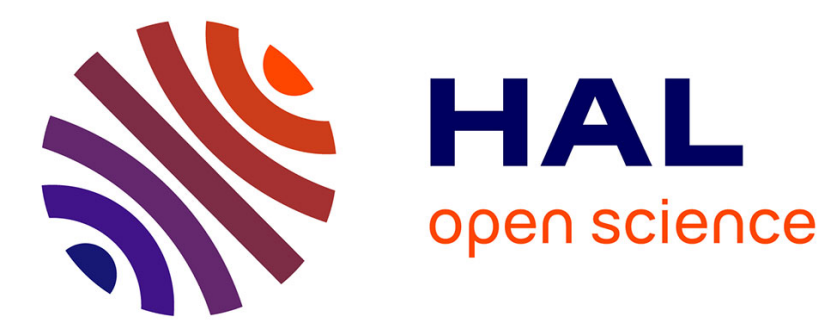

\title{
The core of voting games: a partition approach
}

Aymeric Lardon

\section{To cite this version:}

Aymeric Lardon. The core of voting games: a partition approach. International Game Theory Review, 2015, 17 (3), 10.1142/S0219198915500012 . halshs-00544034v2

\section{HAL Id: halshs-00544034 \\ https://shs.hal.science/halshs-00544034v2}

Submitted on 16 Mar 2015

HAL is a multi-disciplinary open access archive for the deposit and dissemination of scientific research documents, whether they are published or not. The documents may come from teaching and research institutions in France or abroad, or from public or private research centers.

Copyright

L'archive ouverte pluridisciplinaire HAL, est destinée au dépôt et à la diffusion de documents scientifiques de niveau recherche, publiés ou non, émanant des établissements d'enseignement et de recherche français ou étrangers, des laboratoires publics ou privés. 


\title{
The core of voting games: a partition approach
}

\author{
Aymeric Lardon \\ University of Nice Sophia-Antipolis \\ GREDEG - CNRS, 250 rue Albert Einstein \\ 06560 Valbonne, France \\ Aymeric.LARDON@unice.fr
}

October 7, 2014

\begin{abstract}
The purpose of this article is to analyze a class of voting games in a partition approach. We consider a society in which coalitions can be formed and where a finite number of voters have to choose among a set of alternatives. A coalition is winning if it can veto any proposed alternative. In our model, the veto power of a coalition is dependent on the coalition formation of the outsiders. We show that whether or not the core is non-empty depends crucially on the expectations of each coalition regarding outsiders' behavior when it wishes to veto an alternative. On the one hand, if each coalition has pessimistic expectations, then the core is non-empty if and only if the dimension of the set of alternatives is equal to one. On the other hand, if each coalition has optimistic expectations, the non-emptiness of the core is not ensured.
\end{abstract}

Keywords: Voting games; Partition approach; Core.

JEL Classification: C71, D72.

\section{Introduction}

Voting games represent a special class of cooperative games in which some coalitions of voters have the power to enforce their will regardless other voters' actions, while the remaining coalitions are powerless to influence the outcome. A natural concept to predict the outcome of a vote is the core. An alternative belongs to the core if there does not exist some alternative and a winning group of voters in favor of changing the status quo to that alternative. Although voting games constitute a rather special class of cooperative games, the existence of a core alternative is by no means ensured: the famous "paradox of voting" is an elementary three-player example for which the core is empty.

A voting game is viewed as a society in which coalitions can be formed and where a finite number, $n \in \mathbb{N}$, of voters have to choose an alternative from a set in the $p$-dimensional Euclidean space $\mathbb{R}^{p}$. The classification of voting games according to the emptiness or non-emptiness of the core has been the object of a 
wide literature. Assuming that the preference relation over the set of alternatives of each voter is continuous and convex, Greenberg (1979) showed that if the set of winning coalitions of a voting game consists of all coalitions with more than $p n /(p+1)$ individuals then the core is non-empty. In the same way, Nakamura (1979) determined the upper bound on the cardinality of the set of alternatives of a voting game, called the Nakamura number, which would guarantee the existence of a core alternative. The Nakamura number is defined as the size of the smallest collection of winning coalitions having an empty intersection. If such a collection does not exist, then the Nakamura number is equal to infinity. So, the non-emptiness of the core is directly related to the combinatorial structure of the winning coalitions. Schofield (1984), Strnad (1985) and Le Breton (1987) have generalized Greenberg's result (1979) to arbitrary voting games. More precisely, they prove that if $p$ is smaller than or equal to the Nakamura number of a voting game minus two, and if individual preference relations are continuous and convex then the core is non-empty. Otherwise, if $p$ is strictly greater than the Nakamura number of a voting game minus two, there exists a profile of preference relations for which the core is empty.

Coalition formation games with externalities were first modeled by Thrall and Lucas (1963) as partition function games. For this class of games, Hafalir (2007) shows that a convexity property ensures the non-emptiness of the core with singleton and cautious expectations on the coalition formation of the outsiders. Funaki and Yamato (1999) study the core of an economy with a common pool resource by means of partition function games. On the one hand, if each coalition has pessimistic expectations on outsiders' behavior, then the core is non-empty. On the other hand, if it has optimistic expectations, the core is empty when there are more than four players.

In continuation of these works, we study the class of voting games in a partition approach. In particular, we investigate whether it is possible to guarantee the non-emptiness of the core when each coalition is embedded into a partition. A coalition embedded into a partition is winning if it can veto any proposed alternative. Unlike classical voting games, a coalition can be winning for a partition and non-winning for another partition. In other words, whether or not a coalition is winning depends on the coalition formation of the outsiders, and so the nonemptiness of the core too.

On the one hand, assume that the members of a coalition pessimistically expect that the outsiders react in the worst possible way for them when they wish to veto an alternative. In the present model, this will correspond to the case where outsiders will form the largest possible coalition. We prove that the core is non-empty if and only if the dimension of the set of alternatives is equal to one. On the other hand, assume that the members of a coalition optimistically expects that the outsiders react in the best way for them when they wish to veto an alternative. In the present model, this will correspond to the case where each outsider will form a singleton. We show that there always exists a profile of preference relations for which the core is empty. Therefore, whether or not the core is non-empty 
depends crucially on the expectations of each coalition about outsiders' behavior when it wishes to veto an alternative.

This article is organized as follows. Section 2 describes voting games in a partition approach. In section 3 we prove that the core is non-empty when each coalition has a pessimistic view regarding the coalition formation of the outsiders. In section 4 , we show that there exists a profile of preference relations for which the core is empty when expectations of each coalition are optimistic regarding the coalition formation of the outsiders. Section 5 gives some concluding remarks.

\section{The model}

The society consists of a set of voters $N=\{1, \ldots, n\}$ where $n \geq 3$. The voters have to choose an alternative from a non-empty, convex and compact set $X \subseteq \mathbb{R}^{p}$, $p \in \mathbb{N}$. Each voter $i \in N$ has preferences represented by a complete preorder $\geq_{i}$ over $X$. We denote by $\mathcal{P}$ the set of complete preorders over $X$. A profile of preference relations is an element $\geq=\left(\geq_{1}, \ldots, \geq_{n}\right) \in \mathcal{P}^{n}$. We denote by $\mathcal{P}_{c o} \subseteq \mathcal{P}$ the set of continuous, ${ }^{1}$ convex $^{2}$ and complete preorders over $X$.

We denote by $\Omega(N)$ and $\Pi(N)$ the sets of all non-empty coalitions and all partitions of $N$ respectively. Let $S$ and $\rho$ be the representative elements of $\Omega(N)$ and $\Pi(N)$ respectively. The binary relation $\leq^{C}$ on $\Pi(N)$ is defined as follows: we say that a partition $\rho \in \Pi(N)$ is coarser than a partition $\rho^{\prime} \in \Pi(N)$ (or $\rho^{\prime}$ is finer than $\rho$ ) which we write $\rho^{\prime} \leq^{C} \rho$ if for any coalition $S \in \rho^{\prime}$ there exists a coalition $T \in \rho$ such that $T \supseteq S$.

Let $W^{e}$ be a correspondence defined from $\Pi(N)$ to $\Omega(N)$ that associates to each partition $\rho \in \Pi(N)$ a (possibly empty) set of winning coalitions such that $W^{e}(\rho) \subseteq \rho$. Throughout this article, we assume that $W^{e}$ satisfies the two following conditions:

- Proper (P): for any $\rho \in \Pi(N)$, we have $\left|W^{e}(\rho)\right| \leq 1$;

- Splitting of Outsiders (SO): for any $\rho \in \Pi(N)$ and any $\rho^{\prime} \in \Pi(N)$ such that $\rho^{\prime} \leq^{C} \rho$ and $S \in \rho \cap \rho^{\prime}, S \in W^{e}(\rho)$ implies $S \in W^{e}\left(\rho^{\prime}\right)$.

Condition $(\mathrm{P})$ means that any partition $\rho \in \Pi(N)$ admits at most one winning coalition while condition (SO) specifies that a winning coalition $S \in \Omega(N)$ for a partition $\rho \in \Pi(N)$ is still winning when the other coalitions embedded into $\rho$ split into smaller groups.

Definition 1 A voting game in a partition approach is a pair $\left(N, W^{e}\right)$ where $N$ is a set of voters and $W^{e}$ is a correspondence of winning coalitions.

\footnotetext{
${ }^{1}$ A preorder $\geq_{i}$ over $X$ is continuous if for all $x \in X$, the sets $\left\{y \in X: x \geq_{i} y\right\}$ and $\left\{y \in X: y \geq_{i} x\right\}$ are closed relative to $X$.

${ }^{2} \mathrm{~A}$ preorder $\geq_{i}$ over $X$ is convex if $\left[\forall x, y, z \in X, y \geq_{i} x\right.$ and $\left.z \geq_{i} x\right] \Longrightarrow\left[\lambda y+(1-\lambda) z \geq_{i} x\right]$ for all $\lambda \in[0,1]$.
} 
In the general framework of partition function games, the worth of a coalition depends on the entire coalition structure. Any deviation happens with certain expectations of the deviating coalition about the coalition formation of the outsiders. Hafalir (2007) has proceed under the assumption of given expectations of the deviating coalition (singleton, cautious, merging and rational expectations) about outsiders' behavior. ${ }^{3}$ The coalition structure affects the worth of a coalition according to the type of externalities. Externalities are positive (negative) if a merger between two coalitions makes other coalitions better (worse) off. For instance, in partition function games associated with a price competition setting externalities are positive since a merger between two cartels (coalitions) of firms causes an increase of prices which benefits to the other cartels by increasing their market share.

For the class of voting games in a partition approach, whether or not a coalition is winning depends on the coalition formation of the outsiders, and so the outcome of a vote too. Thus, we have to make assumptions about what a coalition conjectures about outsiders' behavior when it wishes to veto an alternative. By $(\mathrm{P})$, there is at most one winning coalition for each partition. In this article, we focus on the two extreme cases of pessimistic and optimistic expectations about the coalition formation of the outsiders. By (SO), externalities are negative since a merger between two coalitions can make coalition $S$ non-winning. So condition (SO) implies that the worst coalition formation for $S$ is that outsiders form the largest possible coalition which corresponds to partition $\rho_{S}^{\top}=\{S, N \backslash S\}$. In the same way, condition (SO) implies that the best coalition formation for $S$ is that each outsider forms a singleton which corresponds to partition $\rho_{S}^{\perp}=\{S\} \cup\{\{j\}: j \in N \backslash S\}$. While pessimistic expectations correspond to cautious and merging expectations as defined by Hafalir (2007) for general partition function games, optimistic expectations coincide with singleton expectations. ${ }^{4}$ With these notations in mind, we can define the core with pessimistic and optimistic expectations.

Definition 2 Let $\left(N, W^{e}\right)$ be a game. The core with pessimistic expectations is the set of all alternatives that will not be vetoed by a winning coalition expecting the worst coalition formation, i.e.

$$
C^{p e s}\left(N, W^{e}\right)=\left\{x \in X: S \in W^{e}\left(\rho_{S}^{\top}\right) \Longrightarrow \nexists y \in X: \forall i \in S, y>_{i} x\right\} .^{5}
$$

Similarly, the core with optimistic expectations is the set of all alternatives that will not be vetoed by a winning coalition expecting the best coalition formation, i.e.

$$
C^{o p t}\left(N, W^{e}\right)=\left\{x \in X: S \in W^{e}\left(\rho_{S}^{\perp}\right) \Longrightarrow \nexists y \in X: \forall i \in S, y>_{i} x\right\}
$$

\footnotetext{
${ }^{3}$ We refer to Hafalir (2007) for a detailed analysis of these expectations.

${ }^{4} \mathrm{~A}$ deviating coalition has rational expectations when it expects that outsiders will try to maximize the sum of their own payoff. In our model, such expectations cannot be defined since voters have individual preference relations on the set of alternatives.

${ }^{5}$ The binary relation $>_{i}$ represents the asymmetric component of $\geq_{i}$.
} 
The connections between $C^{\text {pes }}\left(N, W^{e}\right)$ and $C^{\text {opt }}\left(N, W^{e}\right)$ are emphasized by the following result.

Proposition 1 Let $\left(N, W^{e}\right)$ be a game. Then $C^{o p t}\left(N, W^{e}\right) \subseteq C^{p e s}\left(N, W^{e}\right)$.

Proof: Assume that $x \in C^{o p t}\left(N, W^{e}\right)$ and by contradiction that $x \notin C^{p e s}\left(N, W^{e}\right)$, i.e. there is $S \in W^{e}\left(\rho_{S}^{\top}\right)$ and $y \in X$ such that $y>_{i} x$ for each $i \in S$. By $(\mathrm{P})$ and (SO), we know that $S$ is the unique winning coalition for all $\rho \in \Pi(N)$ such that $S \in \rho$. In particular, this is true for $\rho_{S}^{\perp}$ which contradicts the assumption that $x \in C^{o p t}\left(N, W^{e}\right)$.

As mentioned above, we want to analyze the non-emptiness of the core with pessimistic and optimistic expectations. This is the purpose of Sections 3 and 4 respectively. In the remainder of this section we give the definitions of a classical voting game and the associated core solution concept which will be useful for the sequel.

Definition $3 A$ (classical) voting game is a pair $(N, W)$ where $N$ is a set of voters and $W$ is a set of winning coalitions.

Whether or not a coalition is winning does not depend on the coalition formation of the outsiders. The definition of the core is simplified too.

Definition 4 Let $(N, W)$ be a game. The core is the set of all alternatives that will not be vetoed by a winning coalition, i.e.

$$
C(N, W)=\left\{x \in X: S \in W \Longrightarrow \nexists y \in X: \forall i \in S, y>_{i} x\right\}
$$

\section{The core under pessimistic expectations}

In this section, we study the core in the case where the expectations of each coalition are pessimistic. For this purpose, being given a game $\left(N, W^{e}\right)$ we introduce the associated voting game $\left(N, W_{\text {pes }}\right)$ where $W_{\text {pes }}$ is the set of winning coalitions facing the largest possible coalition. Formally,

$$
W_{\text {pes }}=\left\{S \in \Omega(N): S \in W^{e}\left(\rho_{S}^{\top}\right)\right\}
$$

The result below establishes an equivalence between $C^{\text {pes }}\left(N, W^{e}\right)$ and $C\left(N, W_{\text {pes }}\right)$ and follows directly from (1).

Fact 1 Let $\left(N, W^{e}\right)$ be a game. If we consider the transformation from $\left(N, W^{e}\right)$ to $\left(N, W_{\text {pes }}\right)$ given by $(1)$, then $C^{\text {pes }}\left(N, W^{e}\right)=C\left(N, W_{\text {pes }}\right)$. 
In order to analyze the non-emptiness of the core with pessimistic expectations, we need some results established for classical voting games, in particular those of Nakamura (1979) and Le Breton (1987). As discussed in the introduction, Nakamura (1979) proves that the non-emptiness of the core of a voting game $(N, W)$ is directly related to the combinatorial structure of its winning coalitions.

Definition 5 The Nakamura number of a voting game $(N, W)$ is the extended natural number $v(N, W)$ defined as follows:

$$
v(N, W)= \begin{cases}\infty & \text { if } \cap_{C \in W} C \neq \varnothing \\ \min \left\{\left|W^{\prime}\right|: W^{\prime} \subseteq W \text { and } \cap_{C \in W^{\prime}} C=\varnothing\right\} & \text { if } \cap_{C \in W} C=\varnothing\end{cases}
$$

The set $\bigcap_{C \in W} C$ is called the collegium of $(N, W)$ and its members the vetoers. If it is empty, then the game $(N, W)$ is non-collegial.

Among the voting games, the quota games have received much attention. A quota game is a voting game $(N, W)$ such that there exists an integer $q \leq n$ satisfying $S \in W$ if and only if $|S| \geq q$. For these games, the following result (Moulin 1991) holds :

Lemma 1 Let $(N, W)$ be a quota game. Then its Nakamura number is given by $v(N, W)=\lceil n /(n-q)] .^{6}$

For voting games, a necessary and sufficient condition for the non-emptiness of the core has been provided by Le Breton (1987).

Theorem 1 (Le Breton 1987) Let $(N, W)$ be a game. Suppose that $X$ is a nonempty, convex and compact subset of $\mathbb{R}^{p}, p \in \mathbb{N}$. Then,

(i) if $\operatorname{dim} X \leq v(N, W)-2$, then for all $\geq \in \mathcal{P}_{c o}^{n}$, it holds that $C(N, W) \neq \varnothing ;{ }^{7}$

(ii) if $\operatorname{dim} X \geq v(N, W)-1$, then there exists $\geq \in \mathcal{P}_{c o}^{n}$ such that $C(N, W)=\varnothing$. lemma:

In order to prove the main theorem of this section, we need the following

Lemma 2 Let $\left(N, W^{e}\right)$ be a game. For any coalition $S \in \Omega(N)$ and any coalition $T \in \Omega(N)$ such that $S \in W^{e}\left(\rho_{S}^{\top}\right)$ and $T \in W^{e}\left(\rho_{T}^{\top}\right)$ we have $S \cap T \neq \varnothing$.

Proof: Suppose by contradiction that $S \cap T=\varnothing$. Since $S \in W^{e}\left(\rho_{S}^{\top}\right)$, (SO) implies that $S \in W^{e}(\{S, T, N \backslash(S \cup T)\})$. By $(\mathrm{P})$, we know that $T \notin W^{e}(\{S, T, N \backslash(S \cup T)\})$. We conclude from (SO) that $T \notin W^{e}\left(\rho_{T}^{\top}\right)$, a contradiction.

Lemma 2 establishes that the game $\left(N, W_{\text {pes }}\right)$ is proper, i.e. $S \in W_{\text {pes }}$ and $T \in W_{\text {pes }}$ implies that $S \cap T \neq \varnothing$.

\footnotetext{
${ }^{6}\lceil x\rceil$ is the smallest integer greater than or equal to $x$.

${ }^{7}$ We denote by $\operatorname{dim} X$ the dimension of the affine hull of $X$.
} 
Theorem 2 For any game $\left(N, W^{e}\right)$, it holds that $C^{\text {pes }}\left(N, W^{e}\right) \neq \varnothing$ for all $\geq \in \mathcal{P}_{c o}^{n}$ if and only if $\operatorname{dim} X=1$.

Proof: First, assume that $\operatorname{dim} X=1$. Pick any game $\left(N, W^{e}\right)$ and consider the associated game $\left(N, W_{\text {pes }}\right)$ as in (1). By Lemma 2 we know that $S \cap T \neq \varnothing$ for any coalition $S \in W_{\text {pes }}$ and any coalition $T \in W_{\text {pes. }}$. For the game $\left(N, W_{\text {pes }}\right)$ this implies that $v\left(N, W_{\text {pes }}\right)>2$. Since $\operatorname{dim} X=1$, we conclude by Theorem 1 that $C\left(N, W_{\text {pes }}\right) \neq \varnothing$ for all $\geq \in \mathcal{P}_{c o}^{n}$. We conclude from Fact 1 that $C^{\text {pes }}\left(N, W^{e}\right) \neq \varnothing$ for all $\geq \in \mathcal{P}_{c o}^{n}$.

Then, assume that $\operatorname{dim} X \geq 2$. We show that for any $n \geq 3$ there always exists a correspondence $W^{e}$ such that $C^{\text {pes }}\left(N, W^{e}\right)=\varnothing$ for some $\geq \in \mathcal{P}_{c o}^{n}$. We distinguish four cases:

(a) Assume that $n \geq 6$. For any $\rho \in \Pi(N)$, let us define $W^{e}$ by

$$
W^{e}(\rho)=\{S \in \Omega(N): \forall T \in \rho, T \neq S,|S|>|T|\}
$$

Clearly, $W^{e}$ satisfies (P) and (SO). Moreover, under pessimistic expectations we have

$$
W_{\text {pes }}=\{S \in \Omega(N):|S| \geq\lceil(n+1) / 2\rceil\} .
$$

Thus, when $W^{e}$ is defined by (2) the corresponding voting game $\left(N, W_{\text {pes }}\right)$ is a quota game. By using Lemma 1 , some elementary calculus shows that $v\left(N, W_{\text {pes }}\right)=$ 3 for any $n \geq 6$.

(b) Assume that $n=3$. Let us define $W^{e}$ as follows: $W^{e}(\{\{1,2\},\{3\}\})=\{\{1,2\}\}$, $W^{e}(\{\{1,3\},\{2\}\})=\{\{1,3\}\}, W^{e}(\{\{2,3\},\{1\}\})=\{\{2,3\}\}$, and for all other partitions $\rho \in \Pi(N), W^{e}(\rho)=\varnothing$.

(c) Assume that $n=4$. Let us define $W^{e}$ as follows: for all $\rho_{34} \in \Pi(N \backslash\{1,2\})$, $W^{e}\left(\{\{1,2\}\} \cup \rho_{34}\right)=\{\{1,2\}\}$, for all $\rho_{24} \in \Pi(N \backslash\{1,3\}), W^{e}\left(\{\{1,3\}\} \cup \rho_{24}\right)=$ $\{\{1,3\}\}$, for all $\rho_{14} \in \Pi(N \backslash\{2,3\}), W^{e}\left(\{\{2,3\}\} \cup \rho_{14}\right)=\{\{2,3\}\}$, and for all other partitions $\rho \in \Pi(N), W^{e}(\rho)=\varnothing$.

(d) Assume that $n=5$. Let us define $W^{e}$ as follows: for all $\rho_{345} \in \Pi(N \backslash\{1,2\})$, $W^{e}\left(\{\{1,2\}\} \cup \rho_{345}\right)=\{\{1,2\}\}$, for all $\rho_{245} \in \Pi(N \backslash\{1,3\}), W^{e}\left(\{\{1,3\}\} \cup \rho_{245}\right)=$ $\{\{1,3\}\}$, for all $\rho_{145} \in \Pi(N \backslash\{2,3\}), W^{e}\left(\{\{2,3\}\} \cup \rho_{145}\right)=\{\{2,3\}\}$, and for all other partitions $\rho \in \Pi(N), W^{e}(\rho)=\varnothing$.

For any $n \in\{3,4,5\}, W^{e}$ satisfies $(\mathrm{P})$ and (SO). Moreover, we have $W_{\text {pes }}=$ $\{\{1,2\},\{1,3\},\{2,3\}\}$, and so $v\left(N, W_{\text {pes }}\right)=3$.

In all cases (a), (b), (c) and (d), we conclude from Theorem 1 and Fact 1 that $C^{\text {pes }}\left(N, W^{e}\right) \neq \varnothing$ for all $\geq \in \mathcal{P}_{c o}^{n}$ only if $\operatorname{dim} X=1$.

\section{The core under optimistic expectations}

In this section, we study the core in the case where the expectations of each coalition are optimistic. For this purpose, being given a game $\left(N, W^{e}\right)$ we introduce 
the associated voting game $\left(N, W_{\text {opt }}\right)$ where $W_{\text {opt }}$ is the set of winning coalitions facing singletons. Formally,

$$
W_{\text {opt }}=\left\{S \in \Omega(N): S \in W^{e}\left(\rho_{S}^{\perp}\right)\right\}
$$

The result below establishes an equality between $C^{o p t}\left(N, W^{e}\right)$ and $C\left(N, W_{\text {opt }}\right)$ and follows directly from (3).

Fact 2 Let $\left(N, W^{e}\right)$ be a game. If we consider the transformation from $\left(N, W^{e}\right)$ to $\left(N, W_{\text {opt }}\right)$ given by $(3)$ then $C^{\text {opt }}\left(N, W^{e}\right)=C\left(N, W_{\text {opt }}\right)$.

Under optimistic expectations, we obtain the opposite result to the one under pessimistic expectations.

Theorem 3 For any $\operatorname{dim} X \in \mathbb{N}$, there exists a game $\left(N, W^{e}\right)$ and a profile of preference relations $\geq \in \mathcal{P}_{c o}^{n}$ such that $C^{\text {opt }}\left(N, W^{e}\right)=\varnothing$.

Proof: We distinguish two cases:

(a) Assume that $n \geq 4$. Take $W^{e}$ defined by (2). In this case, under optimistic expectations we have

$$
W_{\text {opt }}=\{S \in \Omega(N):|S| \geq 2\} .
$$

Note that $\left(N, W_{\text {opt }}\right)$ is a quota game and its Nakamura number is given by $\lceil n /(n-2)\rceil=2$ for any $n \geq 4$.

(b) Assume that $n=3$. Let us define $W^{e}$ as follows: $W^{e}(\{\{1\},\{2\},\{3\}\})=\{\{1\}\}$, $W^{e}(\{\{1\},\{2,3\}\})=\{\{2,3\}\}$, and for all other partitions $\rho \in \Pi(N), W^{e}(\rho)=\varnothing$. In this case, we have $W_{\text {opt }}=\{\{1\},\{2,3\}\}$, and so $v\left(N, W_{\text {opt }}\right)=2$.

In both cases (a) and (b), we conclude from Theorem 1 and Fact 2 that for any $\operatorname{dim} X \in \mathbb{N}$, there exists a game $\left(N, W^{e}\right)$ and a profile of preference relations $\geq \in \mathcal{P}_{c o}^{n}$ such that $C^{o p t}\left(N, W^{e}\right)=\varnothing$.

\section{Concluding remarks}

For the class of voting games in a partition approach, we have shown that if each coalition has pessimistic expectations, then the core is non-empty if and only if the dimension of the set of alternatives is equal to one. If each coalition has optimistic expectations, we have proved that the non-emptiness of the core is not ensured. Thus, as in Funaki and Yamato [1999] in the case of an economy with a common pool resource, whether or not the core is non-empty depends crucially on the expectations of each coalition about outsiders' behavior when it wishes to veto an alternative.

Our core existence results hold for a large class of voting games in a partition approach since we only impose the two natural properties $(\mathrm{P})$ and $(\mathrm{SO})$ on the 
correspondence $W^{e}$. A natural extension of our work would be to impose other properties on $W^{e}$ in order to study another class of voting games in a partition approach.

\section{Acknowledgments}

I wish to thank Laurent Mathevet, Sylvain Béal, Philippe Solal and two anonymous referees for providing numerous suggestions that substantially improved the exposition of the article.

\section{References}

[1] Funaki, Y.; Yamato T. The core of an economy with a common pool resource: A partition function form approach. International Journal of Game Theory 1999, $28,157-171$.

[2] Greenberg J. Consistent majority rules over compact sets of alternatives. Econometrica 1979, 47, 627-636.

[3] Hafalir Isa E. Efficiency in coalition games with externalities. Games and Economic Behavior 2007, 61, 242-258.

[4] Le Breton M. On the Core of Voting Games. Social Choice and Welfare 1987, 4, 295-305.

[5] Moulin H. Axioms of Cooperative Decision Making. Cambridge University Press 1991.

[6] Nakamura K. The vetoers in a simple game with ordinal preferences. International Journal of Game Theory 1979, 8, 55-61.

[7] Schofield N. Social equilibrium and cycles on compact sets. Journal of Economic Theory 1984, 33, 59-71.

[8] Strnad J. The structure of continuous-valued neutral monotonic social functions. Social Choice and Welfare 1985, 2, 181-195.

[9] Thrall R.M.; Lucas W.F. N-person games in partition function form. Naval Research Logistic Quarterly 1963, 10, 281-298 